\title{
Work conditions and occupational morbidity in Latvia
}

\author{
M. Eglite ${ }^{1}$, I. Vanadzins ${ }^{1}$, L. Matisane ${ }^{2}$, M. A. Bake ${ }^{1}$, D. Sprudza ${ }^{1}$, \\ Z. Martinsone ${ }^{1}$, I. Martinsone ${ }^{1}$, J. Reste $^{1}$, J. Cirule $^{1}$ \& A. Seile ${ }^{1}$ \\ ${ }^{I}$ Institute of Occupational Safety and Environmental Health of \\ Riga Stradins University, Latvia \\ ${ }^{2}$ Inspecta Prevention, Latvia
}

\begin{abstract}
The aim of study was to analyse work conditions and occupational morbidity in Latvia during a 15-year period for recommendations to employment policy programmes. The study included the analysis of the database of occupational risk factor measurements in more than 7000 enterprises and companies performed in period 1995-2010 by the Laboratory of Hygiene and Occupational Diseases of the Institute of Occupational Safety and Environmental Health of Riga Stradins University. The analysis of registered occupational diseases according to the data from the Latvian State Registry of Occupational diseases run by the Centre of Occupational and Radiation Medicine of Pauls Stradins Clinical University Hospital for the same period was performed. Occupational diseases in Latvia are diagnosed and coded in accordance with the International Classification of Diseases.

Results of measurements showed that for one third of measured occupational risk factors values exceeded recommended limits. The traditional work risk factors (chemical, physical, biological etc.) have been partly replaced by new risks (ergonomic and psychosocial factors). The results of the study indicated that the following enterprises form a major risk group of non-compliance with legislation regarding occupational health and safety: small enterprises; enterprises of private and non-governmental sectors; enterprises of different industries (construction, metal processing and wood processing). The number of firstly diagnosed occupational diseases and patients has gradually increased. The total number of firstly diagnosed and registered occupational patients per 100,000 employees was 11.2 in 1995 and 140.5 in 2009. The structure of
\end{abstract}


occupational diseases shows musculoskeletal diseases (46.1\%) as the leading group of diseases followed by diseases of the nervous system and organs of sense (29.3\%), traumatic disorders and intoxications (11.7\%).

Keywords: work risk factors, occupational morbidity, structure of occupational diseases.

\section{Introduction}

The rapidly changing living environment is closely related to changes in work environment - work becomes more intense and requires maximum attention and concentration, adaption of work with mental and physical capacity of an individual, as well as dealing with different managerial issues [1]. Occupational risk factors occur in all economic sectors and can affect large numbers of employees. Work makes our life reasonable, ensures our independency, affects mental and physical health and facilitates social welfare, however the work environment has a significant impact on the biological processes in the human body and, thus, can directly affect the safety, health and work ability of employees [2]. The health consequences of occupational risk factors, new technologies, unknown effects of existing technologies, create reasons for concern among the working population and people professionally involved in work and health.

It is impossible to maintain a working environment without any risk factors, therefore, reduction and control of risks is a main responsibility of every employer. The occurrence of health effects is often the first indication of occupational risks.

The aim of the study - to analyse work conditions and occupational morbidity in Latvia during a 15-year period for the characterisation of the general situation in the occupational health and safety system in Latvia and for recommendations to changes in employment policy programmes.

\section{Materials and methods}

The database of measurements of occupational risk factors in more than 7000 enterprises and companies performed in the period 1995-2010 by the Laboratory of Hygiene and Occupational Diseases of the Institute of Occupational Safety and Environmental Health of Riga Stradins University was analysed. The Laboratory is accredited for measurements of risk factors according to LVS EN ISO/IEC17025. The database comprises the assessment of 11 physical risk factors in 30,082 workplaces.

The following risk factors were most frequently measured: the noise level was measured in 4480 workplaces (according to 4 different parameters: $8 \mathrm{~h}$ mean equivalent noise level, maximum noise, peak sound pressure, equivalent noise level); whole-body vibration - measurements were carried out in 1145 workplaces and hand-arm vibration measurements of 582 workplaces; microclimate (indoor air), including ventilation assessment were performed in 11,483 workplaces (4 different parameters: relative air humidity - in 3729 
workplaces, air temperature in 3782 workplaces, air velocity - in 36,505 workplaces, ventilation in 322 premises); lighting - in 12,392 workplaces.

The database also comprises wide-ranging information on chemical substances - altogether 93 chemical substances (e.g., organic solvents in varnish, paint, synthetic detergents) and aerosols of dust (e.g., welding fumes, abrasive dust, wood dust) are included in the database, measurements of which were carried out in more than 5000 workplaces. Various ISO methods and modern measuring equipment were used, such as the detection of concentration of solvents and organic compounds in the working environment were performed using the gas chromatograph Varian 3800 with FID and ECD detectors and measurements of metals were done using the atomic absorption spectrophotometer (Varian Spectra AA) with graphite furnace and electrothermal atomisation with Zeeman background correction).

Altogether, organic solvent measurements were made in 2679 workplaces, in the breathing zone of worker, by using individual sample taking devices. The occupational exposure measurements of organic solvents were carried out in 290 companies and their branches of 22 sectors of economy (company codes according to NACE classification) [3]. To get more representative information, the measurements of occupational exposures of 30 organic solvents that are included in the database are analysed, joining them on the basis of similar structure in 8 groups: aromatic hydrocarbons, summary hydrocarbons, esters, ketones, petroleum distillates, celosolves, halogen hydrocarbons and alcohols.

For the assessment of probability of health risk caused by the occupational exposure to a chemical factor in the working environment, the exposure index (EI) is being used, which shows the degree of occupational exposure of a chemical substance and at the same time provides information on the probability of the effect of a chemical substance on workers' health [according to EN 689]. The exposure index is determined relating the actual concentration of chemical substance in the working environment to the occupational exposure limit value set out in the legislation for each substance (OEL). By applying the exposure index one can carry out an assessment of joint exposure risk of different chemical substances irrespective of their individual numerical values.

The exposure indexes of chemicals with low, medium and high exposure degrees are divided into three groups/classes. The first group with the exposure index less than or equal to 0.1 shows a low exposure probability of chemical substance. The second group $(0.1<\mathrm{EI} \leq 0.75)$ shows a medium exposure probability. The third group (EI $>0.75$ ) reflects a high exposure probability.

The following risk factors were assessed also: biologic factors (e.g., organisms causing tick-borne encephalitis, viral hepatitis B and C, HIV/AIDS); mechanic factors (e.g., work with equipment and with dangerous equipment, work at height, work in an explosive atmosphere); ergonomic factors (e.g., awkward posture, repetitive movements, lifting of heavy objects); psychosocial factors (e.g., shortage of time, overtime work, work at night, bad relationships with superiors and colleagues, conflicts).

The analysis of registered occupational diseases according to the data from the Latvian State Registry of Occupational Diseases run by Centre of 
Occupational and Radiation Medicine of Pauls Stradins Clinical University Hospital for the same period was performed.

The term "occupational disease" in Latvia is defined as follows: Occupational diseases are diseases characteristic to certain categories of employees, which are caused by physical, chemical, hygienic, biological and psychological factors in the working environment. Occupational diseases in Latvia are diagnosed and coded in accordance with the International Classification of Diseases. Currently, the effective classification in Latvia is the $43^{\text {rd }}$ International Statistical classification of Diseases and related Health Problems (ISC-10), which is confirmed with the decree No. 20 of January 17, 1996 of the Ministry for Welfare of Republic of Latvia. This classification has been adopted in Latvia without modifications, which allows for the comparison between countries.

The work analysed the absolute number of first time registered occupational diseases patients, as well as the absolute number of initially registered occupational diseases. In order to characterise the rate of cases of occupational diseases in dynamics, the sickness incidence ratio was used - cumulative incidence (CI). It is a quotient, which is calculated according to the following equation: $\mathrm{CI}=$ the number of persons suffering from occupational diseases as a first time occurrence within 1 calendar year / 100,000 of the employed in Latvia at the beginning of the year. Absolute numbers of new cases of occupational diseases were recalculated per 100,000 employees for adequate comparison of occupational morbidity in Latvia with that of other EU Member States.

The statistical processing of the study results was implemented by employing SPSS 14.0 software (company SPSS Ltd., USA). In the statistical data analyses, adequate methods were used [4].

\section{Results}

\subsection{Analysis of database of measurements}

Analysis of measurement database of the Hygiene and Occupational Diseases Laboratory of the Institute of Occupational and Environmental Health of the Riga Stradins University helped to assess compliance of the measured values with mandatory or recommended standards summarised in fig. 1. As reflected, more than one third of measured values of most occupational risks exceeded mandatory or recommended limits (norms). According to the database of work environment measurements, improper microclimate (inappropriate air temperature, too low or too high relative air humidity, as well as too low or too high air movement) should be considered as the most problematic issue. Bad microclimate itself causes neither occupational diseases, nor workplace accidents. However, it negatively affects subjective condition and work ability of employees, thus decreasing quantity and quality of the performed job, and could aggravate already prevalent diseases. For example, draught can worsen the course of musculoskeletal disorders. An inappropriate microclimate is mostly found in offices with bad air exchange and insufficient ventilation, in outdoor sheltered and semi-sheltered workplaces, as well as in workshops having 
draught. Another essential occupational risk according to the database is dust, especially abrasive dust caused by abrasive tools (e.g., polishing equipment) and welding fumes.

More than a third part of the analysis of physical factors - vibration (36\%), noise (44\%), and lightening (46\%) do not conform to corresponding mandatory or recommended values, fig. 1 .

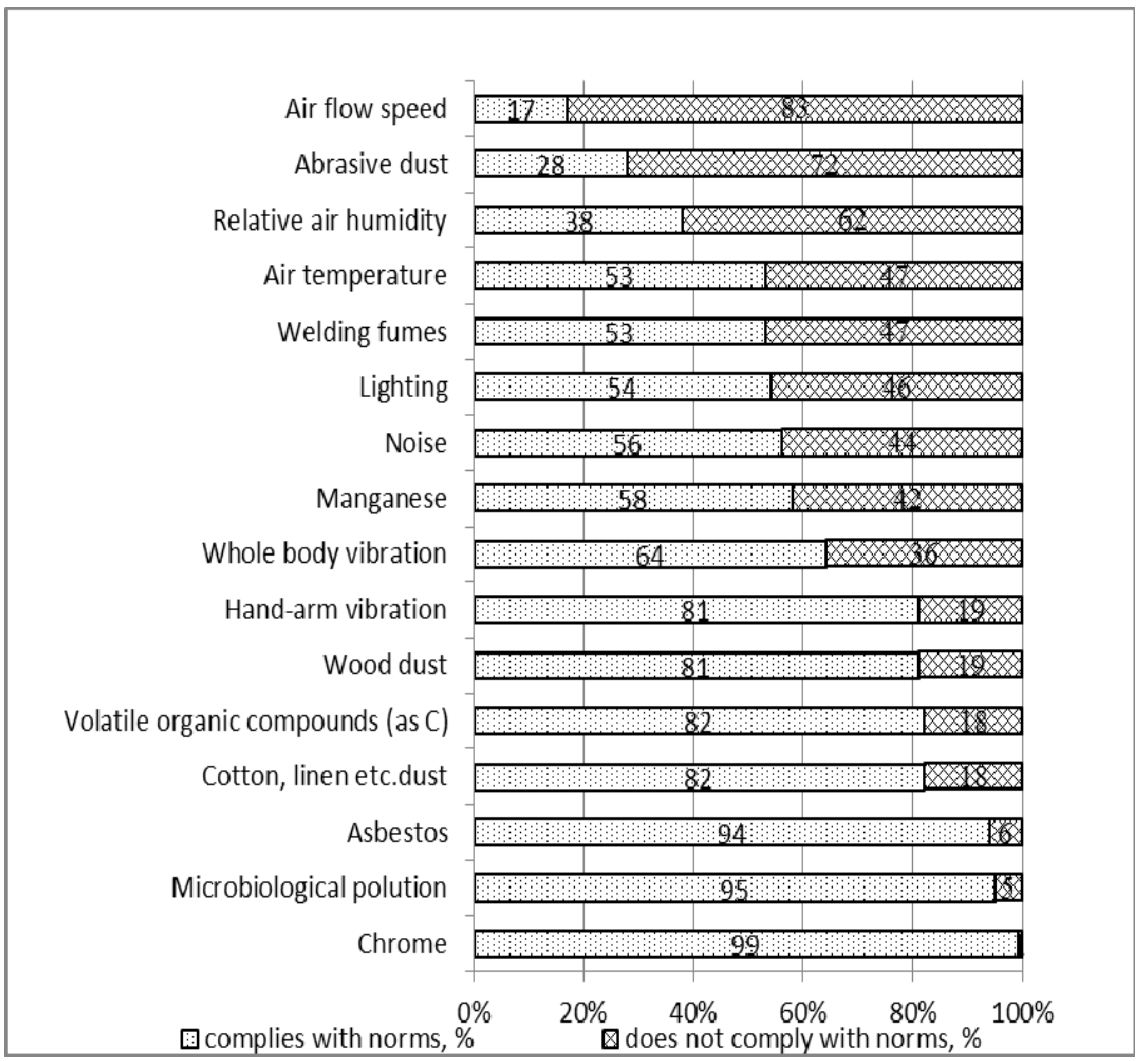

Figure 1: Compliance of occupational risk factors with norms or recommended standards (\% of carried out measurements) in Latvia in the period 1995-2009.

The results of measurements on organic solvent groups showed that toluene, xylenes and benzene were the common pollutants (47\% of measurements). $19 \%$ of measurements consist of determined aliphatic hydrocarbons as the sum calculated according to the amount of carbon $\mathrm{mg} / \mathrm{m}^{3}$. Widespread alcohols from measurements were isopropanol, butanol and ethanol. In the 240 measurements of esters butyl acetate, ethyl acetate and methyl acrylate were predominating. The petroleum distillates were represented mostly by white spirit (lackbensin) or ligroin (a saturated hydrocarbon petroleum fraction) - 195 measurements. 75\% 
of measured halogenated hydrocarbons in the working environment were perchloroethylene in dry cleaning offices. The number of measurements of assessed workplaces for solvents according to the exposure indexes group (low, medium and high) is presented in table 1 . The results show that $18 \%$ of measured solvents have high exposure levels (exposure index $>0.75$ ).

Table 1: $\quad$ Number of measurements of assessed workplaces for solvents in definite (low, medium and high) exposure indexes group.

\begin{tabular}{|l|r|r|r|}
\hline \multirow{2}{*}{\multicolumn{1}{|c|}{ Solvent group }} & \multicolumn{3}{c|}{ Exposure index } \\
\cline { 2 - 4 } & \multicolumn{1}{|c|}{ low } & medium & \multicolumn{1}{c|}{ high } \\
\hline Aromatic hydrocarbons & 435 & 132 & 76 \\
\hline Celosolves & 36 & 9 & 28 \\
\hline Esters & 89 & 37 & 14 \\
\hline Halogen hydrocarbons & 12 & 17 & 74 \\
\hline Ketenes & 77 & 11 & 4 \\
\hline Petroleum distillate & 58 & 62 & 20 \\
\hline Alcohols & 162 & 68 & 33 \\
\hline Summary hydrocarbons & 146 & 114 & 76 \\
\hline Total & 1015 & 450 & 325 \\
\hline
\end{tabular}

The analysis of results of occupational exposure measurements of organic solvents carried out in different sectors according to NACE classification expressed by exposure indexes are presented in table 2 .

The highest level of exposure indexes were revealed in these branches: leather processing and production of leather articles (74\%), public, social and individual services (dry cleaning $-70 \%$ ), manufacturing of equipment, mechanisms and machine tools (29\%).

The traditional work risk factors (chemical, physical, biological) have been partly replaced by new risks (ergonomic - e.g. handling of heavy objects, awkward postures, work with computer, repetitive movements, psychosocial factors - e.g., shortage of time, overtime work, long working hours, conflicts). The analysis showed that improper indoor air quality also should be considered as a significant occupational problem. The results of the study indicated that the following enterprises form a risk group of non-compliance with legislation regarding occupational health and safety: small enterprises; enterprises of private and non-governmental sectors; enterprises of different industries (construction, metal processing and wood processing).

\subsection{Occupational morbidity}

Dynamics in morbidity with occupational diseases in Latvia during the period from 1996 till 2010 characterize the general situation in the occupational health and safety system in Latvia. 
Table 2: Occupational exposure measurements (\%) of organic solvents carried out in sectors of national economy (company codes according to NACE classification) expressed by classes of exposure indexes (EI).

\begin{tabular}{|c|c|c|c|c|}
\hline \multirow[t]{2}{*}{$\begin{array}{l}\text { NACE } \\
\text { code }\end{array}$} & \multirow[t]{2}{*}{ Type of economic activity } & \multicolumn{3}{|c|}{$\begin{array}{c}\text { Number of measurements } \\
\text { by classes of EI }(\%)\end{array}$} \\
\hline & & low & medium & high \\
\hline A & $\begin{array}{l}\text { Forestry, timber preparation and } \\
\text { related services }\end{array}$ & 60 & 40 & 0 \\
\hline DA & $\begin{array}{l}\text { Foodstuff, beverage and tobacco } \\
\text { production }\end{array}$ & 50 & 50 & 0 \\
\hline DB & Textiles production & 100 & 0 & 0 \\
\hline $\mathrm{DC}$ & $\begin{array}{l}\text { Leather processing and production } \\
\text { of leather articles }\end{array}$ & 26 & 0 & 74 \\
\hline DD & $\begin{array}{l}\text { Production of timber and wood } \\
\text { articles }\end{array}$ & 61 & 35 & 4 \\
\hline $\mathrm{DE}$ & Publishing and printing industry & 65 & 23 & 12 \\
\hline DG & $\begin{array}{l}\text { Production of chemical substances } \\
\text { and chemical fibres }\end{array}$ & 68 & 28 & 4 \\
\hline DH & $\begin{array}{l}\text { Production of rubber and plastic } \\
\text { material articles }\end{array}$ & 40 & 34 & 26 \\
\hline DI & $\begin{array}{l}\text { Production of non-metallic mineral } \\
\text { articles }\end{array}$ & 100 & 0 & 0 \\
\hline DJ & $\begin{array}{l}\text { Production of metal and metal } \\
\text { articles }\end{array}$ & 59 & 30 & 11 \\
\hline DK & $\begin{array}{l}\text { Manufacturing of equipment, } \\
\text { mechanisms and machine tools }\end{array}$ & 28 & 43 & 29 \\
\hline $\mathrm{DL}$ & $\begin{array}{l}\text { Manufacturing of electric and } \\
\text { optical equipment }\end{array}$ & 62 & 19 & 19 \\
\hline DN & Furniture production & 71 & 22 & 7 \\
\hline $\mathrm{E}$ & Power, gas and water supply & 56 & 25 & 19 \\
\hline $\mathrm{F}$ & Construction & 50 & 27 & 23 \\
\hline G & $\begin{array}{l}\text { Repair of motorcars, motorcycles, } \\
\text { household equipment and devices }\end{array}$ & 57 & 22 & 21 \\
\hline I & $\begin{array}{l}\text { Transport, rescue and } \\
\text { communication }\end{array}$ & 48 & 29 & 23 \\
\hline $\mathrm{J}$ & Financial mediation & 0 & 100 & 0 \\
\hline K & $\begin{array}{l}\text { Real estate transactions, lease, } \\
\text { computer services, science and } \\
\text { other commercial services }\end{array}$ & 75 & 18 & 7 \\
\hline $\mathrm{L}$ & $\begin{array}{l}\text { Public administration and defence; } \\
\text { mandatory social insurance }\end{array}$ & 75 & 18 & 7 \\
\hline $\mathrm{N}$ & Health and social care & 59 & 28 & 13 \\
\hline $\mathrm{O}$ & $\begin{array}{l}\text { Public, social and individual } \\
\text { services }\end{array}$ & 20 & 10 & 70 \\
\hline
\end{tabular}


The number of occupational diseases and patients revealed for the first time during a year has been gradually increasing since 1996 until 2009. In 2010 there was a slight decrease in occupational morbidity connected with organisational reasons and changes in the registration system. The total number of firstly diagnosed and registered occupational patients per 100,000 employees was 11.2 in 1996 and 138.6 - in 2009, fig.2.

The number of first time patients in 2009 exceeded that of 1993 by 12 times, but the number of first time diagnoses - by 14.8 times.

In Latvia chronic forms of occupational diseases are most common. On very rare occasions acute or sub-acute cases of occupational diseases or chronic occupational diseases in the initial stages have been recorded.

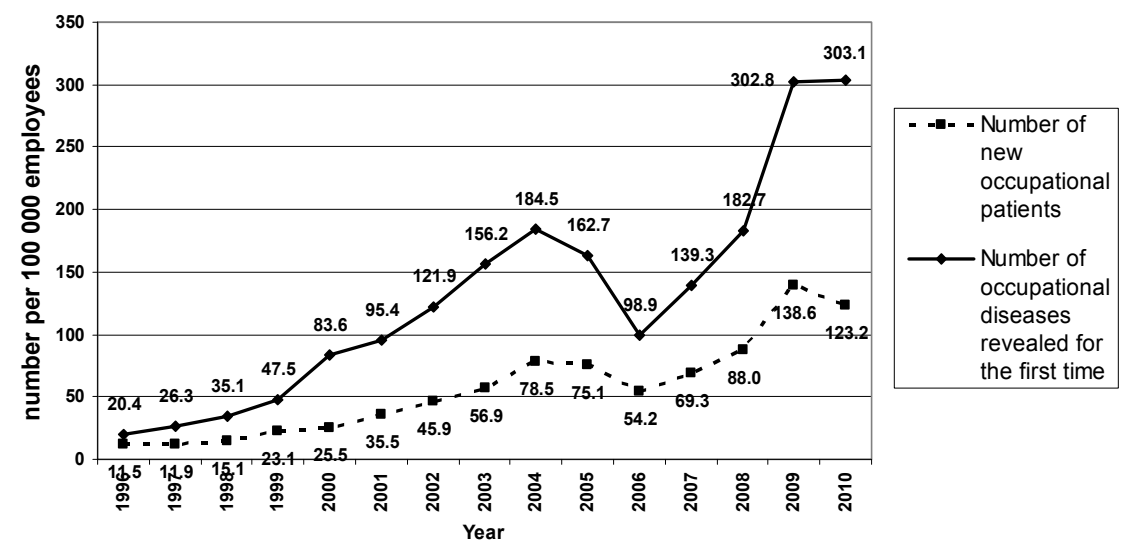

Figure 2: $\quad$ Total number of first time registered occupational diseases patients and occupational diseases in Latvia during 1996-2010 per 100,000 employees.

In Latvia quite often one occupational patient may have several occupational diseases caused by different occupational risks, fig. 3. For example, a carpenter may suffer from loss of hearing due to noise exposure and a respiratory disease due to dust exposure.

The structure of occupational diseases in 2009 shows musculoskeletal diseases $(46.1 \%)$ as the leading group of diseases followed by diseases of the nervous system and organs of sense $(29.3 \%)$ and traumatic disorders and intoxications $(11.7 \%)$.

Similar to the situation worldwide, the structure of occupational diseases in Latvia has changed during 1993 and 2010. Since 1999 there was an increase in morbidity of diseases caused by physical overloads, such as musculoskeletal and connective tissue disorders, as well as carpal tunnel syndrome, but the occurrence of occupational diseases caused by chemical substances and dust has decreased. 


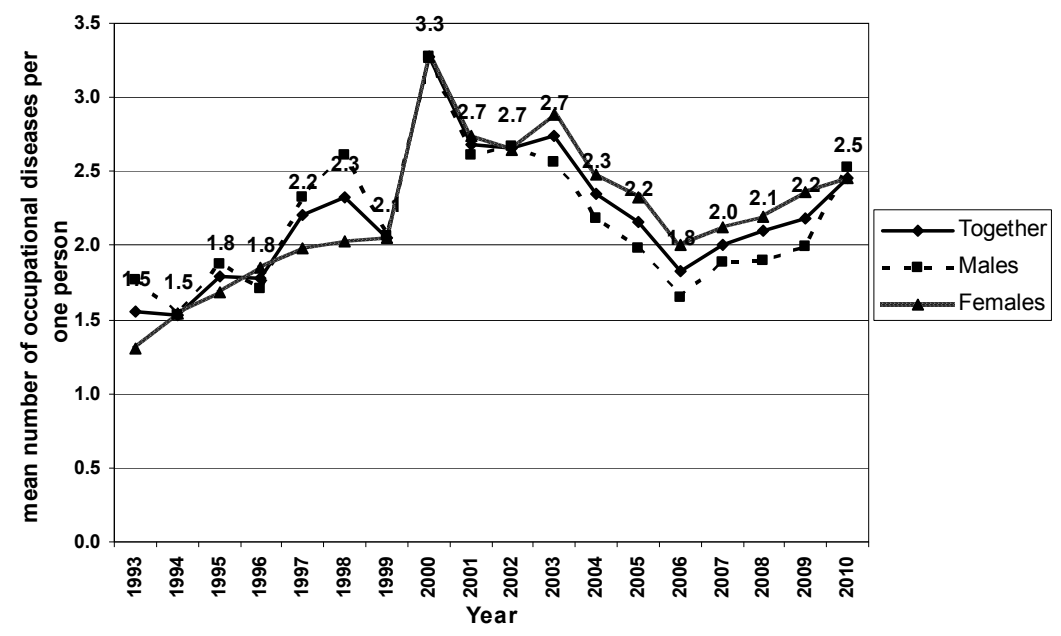

Figure 3: $\quad$ Mean number of occupational diseases per person.

In Latvia musculoskeletal and connective tissue disorders (ICD-10 code M00M90) and carpal tunnel syndrome (ICD-10 code G560) are included in the list of occupational diseases caused by physical overloads (several types of so called ergonomic problems, including the lifting of heavy objects, awkward postures, repetitive movements etc.). The number of certified occupational physicians has increased in the last ten year period as well as the number of compulsory health examinations carried out has increased.

\section{Discussion}

The number of occupational diseases and patients revealed for the first time during a year has been gradually increasing since 1993 until 2010. This is only partly related to the current working environment. Many of the currently revealed health problems are still associated with exposure to occupational risk factors during the last 10-15 years. Supposedly, during the next 5 to 10 years the number of occupational diseases will still continue to grow reaching 250 cases per 100,000 employees. Then, stabilization and even a gradual, slight decrease are expected. Besides, the breakdown of occupational diseases by types has changed. At present musculoskeletal diseases are the most frequently diagnosed occupational diseases, building up to approximately one half of all registered diseases. This group of diseases requires special attention; therefore, it is necessary to build awareness of employers on ergonomic risks of the work environment.

There is a traditional opinion that in Latvian enterprises conventional occupational health problems, such as noise, vibration, dust, chemical substances etc., prevail while EU countries mostly deal with psychosocial, managerial and ergonomic risks. Information obtained during the study shows that at present 
psychosocial factors and ergonomic factors are one of the most essential occupation risk factors in Latvia too. It means that conventional risk factors are substituted by modern ones. On the other hand, laboratory analysis shows that microclimate and dust (especially abrasive dust and welding fumes) should be considered as significant occupational problems. Taking into account that psychosocial and ergonomic risk factors, as well as microclimate, usually interfere with each other and even intensify the effects of one another, this group of factors should be treated with great care $[1,5,6]$.

Measurements of the work environment are not carried out frequently enough. As a result, in most cases occupational risk assessment cannot be considered as being objective. The results of the study show that work environment measurement values exceed mandatory or recommended limit values in one third of cases. It could be explained by the fact that measurements are not carried out in all workplaces, but only in those indicated by the Client (for example, employer, competent specialist or competent authority), and, thus, the most "dangerous" or "hazardous" workplaces are selected

The Latvian State Occupational Diseases Registry mainly contains chronic forms of occupational diseases, which have developed within many years and do not correlate with exposure duration. Therefore, it can be assumed that an increase of occupational morbidity in Latvia is related not only to working conditions but to other factors too. The following other factors could be mentioned: for many years occupational morbidity in Latvia was lower than that of other EU states; therefore, it is probable that due to improved diagnosis and registration of occupational diseases the number of cases registered for the first time will still grow. However, considering amendments in legislation, it is hard to forecast the onset and speed of such an increase in the future. Employees become more aware of occupational risks and signs of occupational diseases; more and more employees are informed on the possibilities of receiving financial support in the case of occupational diseases.

The number of certified occupational physicians has increased and most probably the knowledge of physicians has improved as well. The number of compulsory health examinations carried out has probably increased.

Musculoskeletal diseases are a particular issue, and, according to the data of the Centre of Occupational and Radiation Medicine of Pauls Stradins Clinical Hospital, they belong to the most frequently found occupational disorders in Latvia. One should remember that musculoskeletal diseases are the so called "painful diseases", which often have only short-term effects on working ability. On the other hand, the study reveals that ergonomic risk factors, which cause musculoskeletal problems, prevail in the working environment.

Supposedly, during the next 5 to 10 years the number of occupational diseases will still continue to grow, reaching 250 cases per 100,000 employees. Then, stabilization and even a gradual, slight decrease are expected. Nevertheless, due to amendments in legislation regarding the procedure of occupational diseases diagnostics, the number of occupational diseases could decrease during the next two to three years and after that increase again. This prognosis considers the maximum number of registered occupational diseases in 
European Union countries during the last 15 to 20 years and the situation in Latvia, where occupational risk is still rather high (thus, the development of new occupational diseases are expected), the awareness level of employees is rather low (information of employees would raise their awareness on occupational diseases diagnostics and financial compensations) and diagnostics of occupational diseases will continue to improve [6].

Occupational morbidity in Latvia is considered coherent to occupational morbidity registered in other European countries. It should be noted that, during recent years, occupation morbidity tends to decrease in developed EU countries, while it is still increasing in Latvia. Working conditions in the European Union in general are improving and correspondingly lead to decreased occupational morbidity rates. However, in Latvia improved diagnosis of occupational diseases still outpace improvement of working conditions. The situation in Russia can be compared to that of Latvia in 1996 with no improvements in diagnostics.

\section{Conclusions}

1. Results of the study reveal that the following enterprises are in the at risk group of non-compliance with legislation regarding occupational health and safety, as well as legal labour relations: small enterprises; enterprises of private and non-governmental sectors; enterprises of different industries.

2. Results of measurements showed that one third of measured risk factors values exceed mandatory or recommended limits but the situation has improved in recent years. The results of surveys reveal insufficient assessment of risk factors in workplaces and the selection of the most hazardous or common ones only. However, occupational risk assessment is frequently carried out formally and disregarding legal requirements.

3. The traditional work risk factors (physical, chemical, biological) have been replaced with new ones risks (psychosocial - shortage of time, overtime work, long working hours; ergonomic - work with a computer, handling of heavy objects, awkward posture, and repetitive movements, microclimatic) in Latvia today.

4. The number of occupational diseases and patients revealed annually for the first time has been gradually increasing. The increase of registered occupational diseases is also related to growing awareness of employees, an increasing number of occupational physicians, as well as the possibility to receive monetary compensation.

5. Early diagnosis of occupational diseases during compulsory medical examinations is essential. This will reduce the necessity for compensations from the Special Budget for workplace accidents to be paid in the case of permanent loss of work ability. To facilitate returning of employees into the labour market after occupational illnesses, the focus should be switched to effective rehabilitation.

6. The study indicates that there is a need to improve occupational health and safety legislation, as well as a system for explaining such legal requirements 
and building public awareness; to elaborate several occupational health and safety papers.

\section{References}

[1] Kauppinen, T., Hanhela, R., Heikkilä, P., Kasvio, A., Lehtinen, S., Lindström, K., Toikkanen, J., Tossavainen, A. Work and Health in Finland. In: Changes in work and working conditions in 1997-2006, 2006. http://www.ttl.fi/Internet/English/Information/ Electronic publications/ pdf.

[2] Riedman, A., Bielenski, H., Szczurowska, T., Wagner, A. European Foundation for the Improvement of Living and Working Conditions, Working Time and Work Life Balance in European companies: Dublin, 70 p. 2006.

[3] Glossary: Statistical classification of economic activities in the European Community (NACE) http://epp.eurostat.ec.europa.eu/ statistics_explained/ index.php

[4] Altman, D.G. Practical statistics for medical research. Chapman and Hall: London, 606 pp. 2003.

[5] Rantanen J., Kauppinen T., Lehtinen S., Mattila M., Toikkanen J., Kurpa K., Leino T. Work and health country profiles of twenty two European countries. Finnish Institute of Occupational Health: Helsinki, 444 p, 2002.

[6] Rantanen J., Kauppinen T., Toikkanen J., Kurpa K., Lehtinen S., Leino T. Work and health country profiles and national surveillance indicators in occupational health and safety, In: People and Work. Research Reports 44. Finnish Institute of Occupational Health: Helsinki, 2001. 